\title{
The Use of Asynchronous Learning Networks in Nutrition Education: Student Attitude, Experiences and Performance
}

\author{
Graham Paul Shaw \\ The Department of Basic Medical Sciences \\ Californian College of Podiatric Medicine \\ 1210 Scott Street \\ San Francisco, CA 94115, USA \\ Tel: (415) 292-0456; \\ E-mail: gshaw@ccpm.edu \\ Willy Pieter \\ Department of Physical Education \\ University of Asia and the Pacific \\ Pearl Drive, Ortigas Center \\ Pasig City 1600, MM, Philippines \\ E-mail:m017au00@,cwcom.net
}

\begin{abstract}
In this study a change in teaching strategy to involve a greater emphasis on asynchronous learning networks (ALNs) was implemented and the views of students $(\mathrm{n}=51)$ to this change were evaluated through responses to an online questionnaire. In response to Likert-type questions the majority of students demonstrated a positive view of this new model. Sixty-one percent of students felt that other types of online material would benefit the learning process and $80 \%$ would recommend this module to a friend. Students acknowledged that the use of ALN-supported learning made the material easier to understand (52\%), the lecturer more accessible (66\%) and enabled them to take a more active role in the learning process $(55 \%)$.
\end{abstract}

Though only $10 \%$ of students utilized the asynchronous newsgroup more than 5 times, $77 \%$ found reading the contributions of others useful. Contrary to this $76 \%$ preferred the more familiar lecturebased environment for subject delivery. In response to open-ended questions students' views were more reserved and highlighted a range of problems such as inadequate infrastructure, unreliable computers, and poor access to the online material as well as resistance to a new teaching paradigm. Student performance was influenced by age and contribution to the newsgroup. Those who were younger had a lower grade (47.8 ? 15.8) than those who were older (52.0 ? 11.4). Students with higher grades (56.2 ? 10.3) contributed to the newsgroup while students with lower grades (45.7 ? 12.5) did not.

Based on these observations, it is apparent that students do appreciate the advantages of ALNsupported learning though for a shift toward this model to be effective problems of access and system failure must be resolved. Implications for future ALN-based modules are discussed.

KEY WORDS

ALN, Newsgroups, Infrastructure, Student resistance.

\section{INTRODUCTION}

As the number of students entering higher education in the UK rises so class sizes are increasing to such an extent that lectures are now delivered to large groups of passive recipients of information and 
small group tutorial classes involve over 20 students. At the University of North London student numbers on Life Science courses have increased by $300 \%$ in the past five years. Furthermore, as a consequence of successful recruitment initiatives and our open access policy, the numbers of mature students and individuals from ethnic minority groups attending the university are also increasing. In addition, the number of students from non-science or non-traditional backgrounds (i.e., students who are not 18-year old school leavers) taking science modules continues to rise. Academic staff now deliver the curriculum to larger class sizes containing students of widely differing abilities with ever decreasing resources per student. Set against this background, whilst recognising the limitations of communication and information technologies (C\&IT) -supported learning, the potential benefits of using multimedia in higher education such as the promotion of student-centred learning and opportunity for out-of-class interaction between faculty and students and among students are considerable [1].

At present there is widespread institutional and U.K. government support for a change in teaching strategy to involve a greater emphasis on ALNs to maintain the efficiency and effectiveness of the learning process. Providing courses are appropriately redesigned for delivery via ALNs the rationale for this modification of curriculum delivery is pedagogically sound [2] , [3] , however it may not be appreciated by the students. The new innovations in delivery format suit some students better than others. In particular, mature students who make up an increasing proportion of the total student population at the University of North London may be apprehensive about ALN-supported learning since it is not consistent with their previous learning experiences. The degree to which students accept the use of C\&IT may be influenced by factors such as age and gender; one study [4] has shown that woman can be at a disadvantage.

Though a considerable corpus of evidence is available to support the view that C\&IT-assisted learning is well received by students [5], [6], Phipps and Merisotis [7] suggest that much of the work in this area is of questionable quality and should be viewed with some caution.

In the present study we provide the results of a summative evaluation of the use of ALN-assisted learning in the delivery of a nutrition module. The summative evaluation of this ALN-assisted learning model was carried out within the context of an actual nutrition module using registered students and a standard assessment regimen, giving this study a considerable degree of ecological validity. Students' attitudes, views and experiences were analysed on the basis of their responses to an online questionnaire. These views are significant since a considerable amount of time and effort is currently being spent on developing online courses, generally with no consideration of the views of the user. For ALNs to be effective students must be initially motivated to use the new technology and must be aware of the advantages that the ALN paradigm has to offer.

The purpose of this study is to evaluate the attitudes, views and experiences of a group of nutrition students toward an ALN-assisted learning environment and asynchronous computer-mediated communication. It is envisaged that the results of this study will inform the design of future online modules in the nutrition subject area.

\section{HISTORICAL BACKGROUND}

The majority of modules within The School of Health and Sports Science at the University of North London are organised in a traditional lecture/tutorial/practical/private study format. In an attempt to maintain teaching and learning quality and prompted by the recommendations of an independent review of Higher Education in the U.K., the Dearing Report [ 8 ] a recent course revalidation exercise provided the opportunity to change the mode of curriculum delivery in selected modules.

As part of this revalidation, selected modules in The School of Health and Sports Science at the University of North London were redefined in terms of aims and learning outcomes. In addition, teaching methods were transformed from a traditional approach to one with a greater emphasis on 
ALNs. By increasing the emphasis on ALNs a more flexible approach to curriculum delivery was achieved, giving the students the opportunity to manage their own education by adopting a self-paced learning strategy. It was envisaged that this approach would benefit all students, though particularly the increasing proportion of students who may supplement their grant by part-time employment or those students who have family responsibilities in addition to their studies.

The advanced level (second and third year) module in Nutritional Medicine taken by students of Human Nutrition and Human Nutrition and Dietetics was selected for this exercise.

\section{MODULE DESIGN}

\section{A. Traditional Format}

Prior to the implementation of these recent innovations a "sage on the stage" approach to curriculum delivery was utilised. In this model the curriculum is delivered through traditional linear teacher-led exercises such as lectures or tutorials. In this format the module was delivered over a 12-week teaching semester allowing 48 hours of staff contact. The module was timetabled into a 4-hour teaching block that involved traditional lectures ( $2 \mathrm{hrs})$ supplemented by teacher-led tutorials $(2 \mathrm{hrs})$. The module was assessed through a combination of progress test, essay and end examination.

\section{B. Revised Format}

In the new revised learner-centred format a range of media was utilised for curriculum delivery. No attempt was made to replace the lecturer but a proportion of their role in the learning process was altered to that of a facilitator of student learning. The traditional lectures $(2 \mathrm{hrs})$ were supplemented by alternating virtual and teacher-led tutorials $(2 \mathrm{hrs})$. The curriculum was delivered via a module home page, shown in Figure 1, containing links to lecture synopses, newsgroup, assignments, past papers, library, relevant journals and virtual tutorials. The central design features of a good user interface outlined by Brown [9] were incorporated into the Nutritional Medicine interface. A key component was the fixed navigation frame to the left facilitating navigation and thereby preventing the "lost in hyperspace" phenomenon.

Students were only able to access the lecture synopses, past papers and the virtual tutorials during computer room opening hours $(9.00$ a.m.- 8.30 p.m. Monday to Thursday and from 9.00 a.m.- 4.30 p.m. on Fridays and 10.00 a.m.- 2.30 p.m. on Saturdays) since access was limited to users at local computer terminals.

The virtual tutorials were designed to replace alternate face to face tutorials. During the virtual tutorial sessions students attempted a series of questions designed to build on material covered in the related lecture. By using some simple JavaScript and a HTML frame format students were able to consider the material, then attempt each question and receive immediate feedback. Video footage of surgical techniques and conference proceedings were also used to supplement the traditional lectures and slides from power point presentations, which were available on line.

Since peer interaction has long been acknowledged to play a key role in the learning process [10] the module utilised e-mail and Collabra newsgroups to facilitate asynchronous online communication among students and between students and staff. Newsgroup members could post messages at any time and access was not limited to local terminals. Initially, students (and staff) were encouraged to use the newsgroup either to introduce themselves or to recount their holiday experiences in the case of returning students. In this way the students were able to familiarise themselves with the technology prior to graded assignment. As the module progressed this forum enabled students to organise group work, share resources such as useful web sites and articles as well as clarify problems as they arose. Though current opinion contends that if student contributions to the newsgroup do not form part of the module assessment then participation in online discussion will be limited [11], student participation was encouraged by providing incentives such as revision/coursework tips and reference 
sources. Although students were not required to post assignments to the newsgroup, general feedback, models of good practice and examples of excellent coursework were posted to the newsgroup by staff.

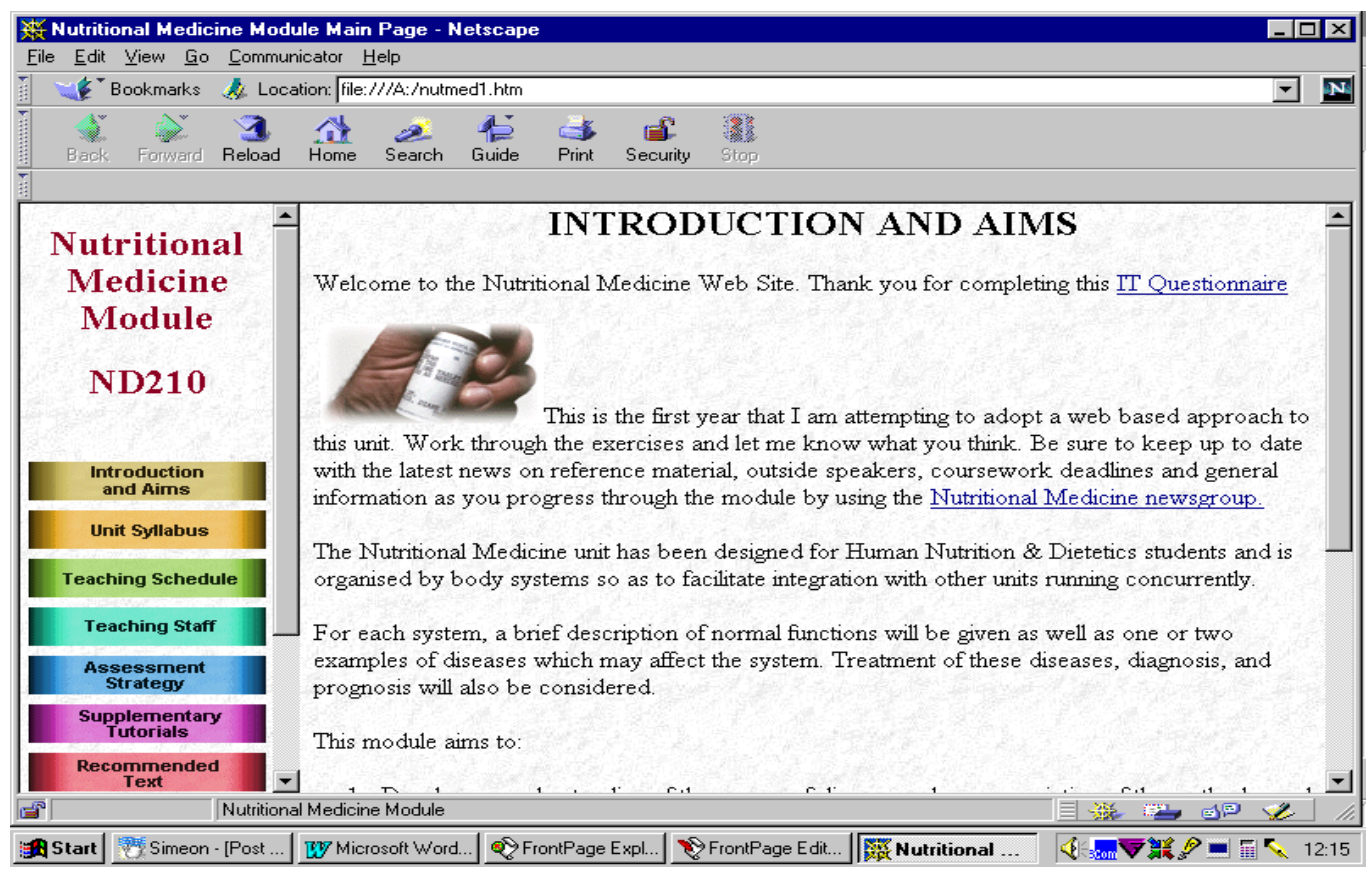

Figure 1: Nutritional Medicine Home Page.

\section{STUDY METHODOLOGY}

Sixty-seven students of Human Nutrition and Human Nutrition and Dietetics (5 males: 62 females) enrolled in the Nutritional Medicine module and 51 (5 males: 46 females) completed the IT Appreciation questionnaire. All students gave informed consent for the content of the ALN to be used in this study. Of the 67 students, 53 successfully completed the module, 10 failed and 4 did not complete (data consistent with previous traditional iterations of the module). This group, minus 2 outliers, was selected for analysis regarding differences in module grade by age group and newsgroup contribution. Of the 51 students who completed the IT Appreciation questionnaire, 44 passed the module, 5 failed and 2 did not complete. Due to outliers, 5 subjects were removed from this data set, leaving 46 students for statistical analysis for the IT Appreciation questionnaire. All students were attending the University of North London in full-time mode. The average age of the participants was $28.2 \pm 7.8$ years (range $20-45$ years). Given that the Universities and Colleges admissions service for the U.K. (UCAS) consider that applicants over the age of 21 years are mature and that Nutritional Medicine is a second year module, for the purpose of statistical analysis students over the age of 22 years were considered mature. None of the participants had previous experience with formal computer-assisted learning though approximately $30 \%$ had access to a computer at home.

Attitude and perception data were obtained through a post-module online IT Appreciation questionnaire completed in class during week 12 of the course. This questionnaire was of low objectivity and high focus [12] (structured questions restricting responses to a narrow range of alternatives) and consisted of 16 statements in either text match or multiple choice formats. Mean responses to the multiple choice questions are shown in Table 1. The text match questions allowed students to express opinions in their own words and the multiple choice format consisted of 5 possible responses (some reversed to counteract response sets) to the given statement arranged in a Likert format [13]. The lower the mean score the stronger the respondents' agreement with the statement, the 
higher the mean score the stronger the respondents' disagreement with the statement. A mean score of 3 indicates a "no opinion" response to the statement. Scores ranged from 1 (strongly agree) to 5 (strongly disagree). The scores from selected individual statements were summed to yield a total IT Appreciation score. The lower the score the greater the appreciation of IT. Responses to the text match questions were grouped according to the most common themes expressed by the respondents. Two experts in the field of online learning independently identified the categories described in this report.

Student contribution to the Collabra newsgroup was determined by manual examination of the transcript.

\section{Statistical Analysis}

To determine the difference in module grade between age group and newsgroup contribution, a 2-way (Age x News) Anova was used. Because of the heteroscedasticity of the distribution of the dependent variable, the data were $\log$ transformed. A multiple forward stepwise regression analysis was employed to assess the variance in grade explained by newsgroup contribution and age. A simple regression analysis was conducted to determine the variance accounted for in grade by newsgroup contribution per age group. To determine the differences in responses to the IT Appreciation questionnaire between those who passed or failed the module, a 1-way Anova was used.

In addition, a multiple forward stepwise regression was employed with statements 3) "I preferred the use of online technology used in this module to more traditional means of delivery," 5) "The use of online technology in this module was a waste of time" and 13) "I think newsgroup contributions should be assessed," and IT Appreciation score as dependent variables with statement 1) "access to a computer terminal was a problem" and the frequency of newsgroup contribution as independent variables. All analyses were conducted with a significance level of 0.05 .

\section{RESULTS}

\section{A. IT Appreciation and Student Performance}

The mean and standard deviation of the student responses to the multiple choice, Likert statements in the online IT Appreciation questionnaire are shown in Table 1. The mean student responses ranged from 2.024 - 4. Only statement 5) "The use of online technology in this module was a waste of time" had a mean response above 4 (disagree), while three statements, 1) "Access to a computer terminal was a problem," 12) "I found reading the newsgroup contributions of others useful" and 14) "I would recommend this module to a friend" had a mean response of 2 (agree). The responses to the remaining statements were generally neutral.

Further analysis of the responses to the multiple choice questions revealed that the majority of students $(65.8 \%)$ felt that the proportion of C\&IT to traditional delivery techniques used in this module was appropriate. Only $24 \%$ of students expressed a preference for C\&IT-supported learning over traditional methods. Seventy-six percent of students considered the lecture to be the most useful mode of information delivery used in this module with only $7.5 \%, 6.25 \%, 5 \%$ and $1.25 \%$ expressing a preference for traditional tutorials, online tutorials, newsgroups and video respectively. Though $60 \%$ of students felt that more modules should employ online technology only $32 \%$ thought that online technology would eventually replace lectures. Sixty-one percent of students felt that other types of online material such as practicals would benefit the learning process and $80 \%$ would recommend this module to a friend.

The majority of students acknowledged that the use of ALNs in this module made the material easier to understand $(52 \%)$, the lecturer more accessible $(66 \%)$ and enabled them to take a more active role in the learning process $(55 \%)$. 


\begin{tabular}{|c|c|c|}
\hline STATEMENT & MEAN & SD \\
\hline 1. Access to a computer terminal was a problem & 2.080 & 1.278 \\
\hline $\begin{array}{l}2 . \text { The proportion of online material to traditional delivery methods } \\
\text { was about right }\end{array}$ & 2.395 & 0.801 \\
\hline $\begin{array}{l}\text { 3. I preferred the use of online technology used in this module to } \\
\text { more traditional means of delivery }\end{array}$ & 3.153 & 0.982 \\
\hline $\begin{array}{l}\text { 4. I think that online technology could eventually replace traditional } \\
\text { lectures }\end{array}$ & 3.412 & 1.168 \\
\hline 5. The use of online technology in this module was a waste of time & 4.095 & 0.781 \\
\hline 6. The use of online technology made the lecturer more accessible & 2.286 & 0.939 \\
\hline $\begin{array}{l}\text { 7. The use of online technology made the material studied in this } \\
\text { module easier to understand }\end{array}$ & 2.602 & 1.047 \\
\hline $\begin{array}{l}\text { 8. The use of online technology made the material studied in this } \\
\text { module more interesting }\end{array}$ & 2.329 & 0.876 \\
\hline $\begin{array}{l}\text { 9. The use of online technology enabled me to take a more active } \\
\text { role in the learning process }\end{array}$ & 2.547 & 0.978 \\
\hline 10. I feel that more modules should employ online technology & 2.393 & 0.982 \\
\hline $\begin{array}{l}\text { 11. I think that other types of online material such as practicals } \\
\text { would benefit the learning process }\end{array}$ & 2.482 & 0.959 \\
\hline 12. I found reading the newsgroup contributions of others useful & 2.024 & 0.732 \\
\hline 13. I think newsgroup contributions should be assessed & 3.767 & 1.025 \\
\hline 14. I would recommend this module to a friend & 2.060 & 0.588 \\
\hline
\end{tabular}

Table 1. Means and Standard Deviations (SD) Of Student Responses to IT Appreciation Questionnaire Statements.

There were generally no significant differences in the responses of successful and unsuccessful students to the statements in the questionnaire. However there were two exceptions. Students who failed the module agreed more (2.3 ? 1.8) with statement 3) "I preferred the use of online technology used in this module to more traditional means of delivery" than those who passed $(3.4$ ? 0.9) [F $(1,44)$ $=4.693, \mathrm{p}=0.036]$. Those who passed the module disagreed more (4.0 ? 1.0) with statement 13) "I think newsgroup contributions should be assessed" than those who failed $(2.8$ ? 1.7) [F $(1,44)=$ $6.007, \mathrm{p}=0.018]$. For those students who passed the module, statement 1 was negatively related $(\mathrm{r}=-$ $0.330)$ to IT Appreciation score and accounted for $10.9 \%(\mathrm{SEE}=5.856)$ of the variance $(\mathrm{p}=0.038)$. In other words, the more the subjects, who passed, indicated that access to a computer terminal was a problem, the higher the IT Appreciation score, i.e., the more they disliked technology and the less they contributed to the newsgroup.

For those who failed, statements about access and the frequency of newsgroup contribution explained $85.6 \%(\mathrm{SEE}=3.789)$ of the variance in IT Appreciation score $(\mathrm{p}=0.026)$. In other words, for those who failed, the more they agreed that access to a computer terminal was a problem (statement 1 ) and the less they contributed to the newsgroup, the more they disliked the online technology.

The majority of students in this study experienced problems gaining access to a computer terminal. Over $78 \%$ of students either agreed or strongly agreed with the statement "access to a computer terminal was a problem." Once these students had gained access to a computer terminal, over $95 \%$ encountered further problems (outlined in Table 2). Analysis of the student responses revealed two general categories of problem, i.e., technical and personal. The problems most commonly stated were of a technical nature, i.e., the limited number of computers available and slow computer response time. 


\begin{tabular}{ll}
\hline TECHNICAL & 36.8 \\
Slow computer response time & 33.8 \\
Limited computer availability & 17.6 \\
Network Problems & \\
PERSONAL & 4.4 \\
Lack of confidence with computers & 2.0 \\
Lack of familiarity with software & 1.0 \\
Others & 4.4 \\
No Problems & \\
\hline
\end{tabular}

Table 2: Students’ Responses To Statement, “Briefly Describe Any Problems Which You Feel Compromised Your Ability To Complete Your Online Study Session."

\section{B. The Use of the Asynchronous Communication Newsgroups}

During the 12 teaching weeks of the semester, 254 contributions were made to the newsgroup. When corrected for duplicate postings the total number of original messages was 209, of which the tutor posted 73. The proportion of students who contributed to the newsgroup throughout the module was limited. Almost $27 \%$ of the students failed to use the newsgroup at all and almost $90 \%$ of students used it less than 5 times (Table 3). However, over $77 \%$ of students found reading the contributions of others worthwhile. Though a variety of reasons were provided for not contributing to the newsgroup two general categories can be identified, i.e., technical and personal (Table 4). The most often quoted was a difficulty in accessing the newsgroup forum.

\begin{tabular}{lc}
\hline FREQUENCY & PERCENTAGE RESPONDENTS \\
\hline 0 & 26.74 \\
$1-5$ & 62.79 \\
$6-10$ & 10.47 \\
$11-15$ & 0.00 \\
Over 15 & 0.00 \\
\hline
\end{tabular}

Table 3: Students' Answers to Question, “How Many Times Did You Contribute to the Newsgroup?”

EXPLANATION $\quad$ PERCENTAGE RESPONDENTS

\section{TECHNICAL}

Difficulties with access

Insufficient computers

PERSONAL

Insufficient time / patience

Lack of interest

Lack of understanding

Afraid of publicity

Others
31.5
11.4
22.8
20.0
5.7
5.7
2.9

Table 4: Students' Answers to Question, "If You DID NOT Contribute to the Newsgroup, Why Not?" 


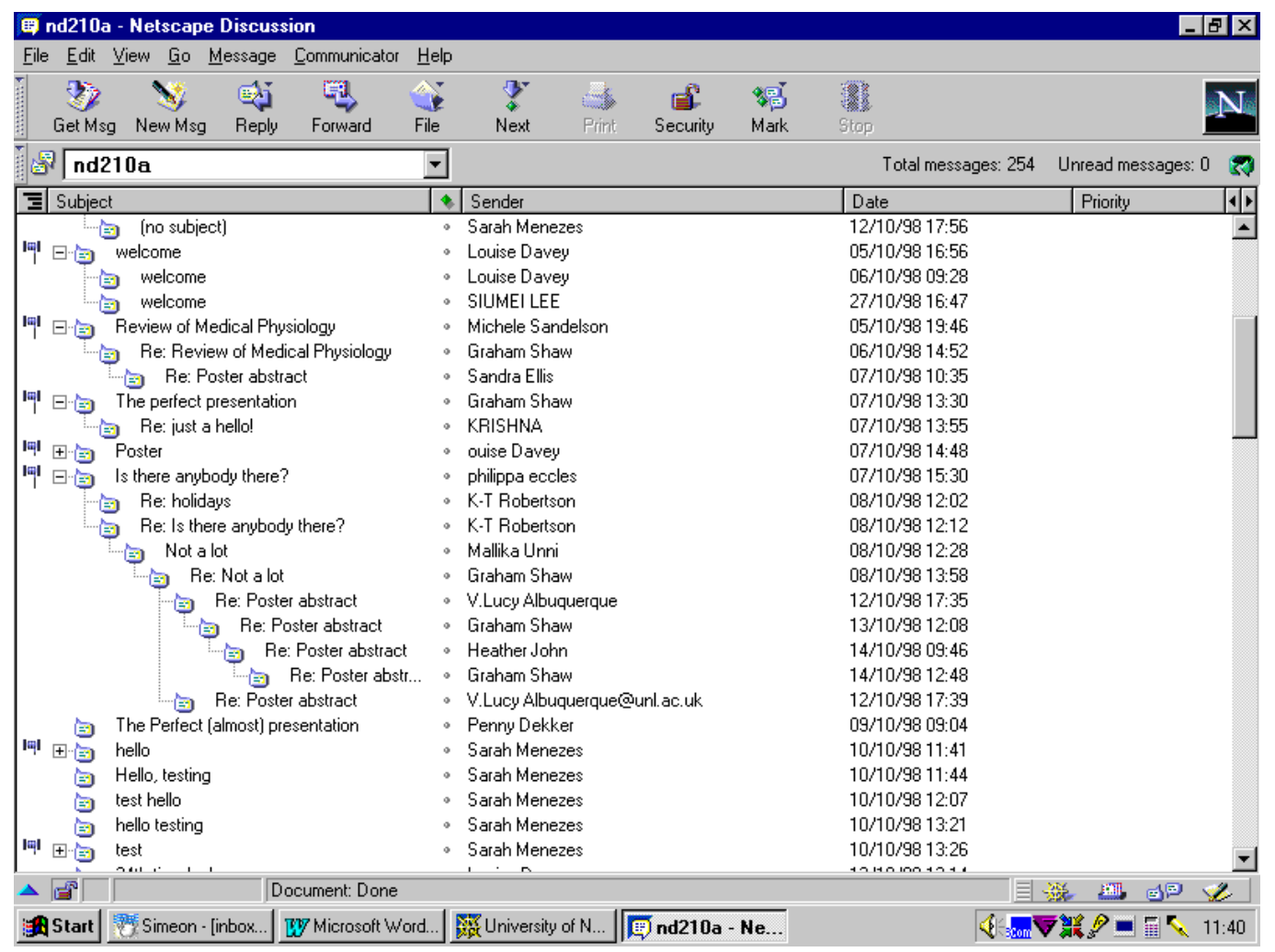

Figure 2. Newsgroup Dialogue.

Table 5 shows the means and standard deviations of age and grade by age group and newsgroup contribution. There was no interaction between age and newsgroup contribution $[\mathrm{F}(1,61)=1.183, \mathrm{p}$ $>0.05]$ for grade. However, there were age $[F(1,61)=6.113, p=0.016]$ and newsgroup contribution $[\mathrm{F}(1,61)=14.278, \mathrm{p}<0.001]$ main effects. Those who were younger had a lower grade $(47.8 \pm 15.8)$ than those who were older $(52.0 \pm 11.4)$. Those who contributed to the newsgroup had a higher grade $(56.2 \pm 10.3)$ than those who did not $(45.7 \pm 12.5)$. Age did not explain any of the variance in grade ( $p$ $>0.05$ ). When analysing the relationship between newsgroup participation and grade separately per age group, the regression analysis revealed that contribution to the newsgroup in only the older students explained $35.6 \%$ of the variance in grade $(\mathrm{SEE}=7.260, \mathrm{p}=0.003)$. Collapsed over age group, contribution to the newsgroup explained $20.4 \%$ of the variance in grade for those who were successful $(\mathrm{SEE}=0.130, \mathrm{p}=0.011)$. However, contribution to the newsgroup did not account for any variance in those who failed the module when collapsed over age.

\begin{tabular}{lcccc}
\hline & $\begin{array}{c}\text { Young } \\
\text { Contribution } \\
\mathrm{n}=10\end{array}$ & $\begin{array}{c}\text { No Contribution } \\
\mathrm{n}=5\end{array}$ & $\begin{array}{c}\text { Mature } \\
\text { Contribution } \\
\mathrm{n}=23\end{array}$ & $\begin{array}{c}\text { No Contribution } \\
\mathrm{n}=27\end{array}$ \\
\hline Age (yrs) & $20.9 ? 0.3$ & $20.8 ? 0.5$ & $33.4 ? 7.7$ & $26.9 ? 6.5$ \\
Grade & $52.7 ? 12.8$ & $37.6 ? 17.6$ & $57.8 ? 8.8$ & $47.2 ? 11.1$ \\
$(\%)$ & & & & \\
\hline
\end{tabular}

Table 5: Means and Standard Deviations of Age and Grade by Age Group and Contribution to the Newsgroup.

\section{Suggested Improvements}

The most frequently suggested improvement was for the implementation of a password access system to facilitate remote access to online material. The remaining suggestions can be grouped as either a call for improvements in infrastructure, i.e., either more or better computers (preferably both) or a 
return to more traditional paradigms of teaching. Almost $10 \%$ of students suggested that no improvements were required.

\begin{tabular}{lc}
\hline IMPROVEMENT & PERCENTAGE RESPONDENTS \\
\hline Password access from home & 23.5 \\
More traditional classes & 23.5 \\
Increased computer availability & 23.5 \\
No improvement required & 9.8 \\
More online slides & 3.9 \\
Smaller class size & 3.9 \\
Others & 11.9 \\
\hline
\end{tabular}

Table 6. Students' Answers to Question, "How Can This Module Be Improved?"

\section{DISCUSSION}

In this study we have presented the attitudes, views and experiences of a cohort of students taking the Nutritional Medicine module delivered using an ALN-based paradigm. The evaluation was carried out as an integral part of the students' degree programme and the results will be used to inform the development of future nutrition modules at The University of North London.

\section{A. IT Appreciation and Student Performance}

Based on the student responses to the multiple choice Likert statements the ALN paradigm used in this study can be considered a success. The majority of respondents agreed with statements suggesting that they have become more independent learners, that the material was easier to understand when presented using this model, the lecturer was more accessible, and this model enabled them to take a more active role in the learning process. Furthermore, the majority of students suggested that more modules should employ online technology $(60 \%)$ and that they would recommend this module to a friend $(80 \%)$. However, the possibility that these positive attitudes toward ALNs expressed in this study may be due to the Hawthorne effect should be considered. Further work is currently in progress involving longitudinal study of students, as they become more familiar with ALNs to assess this effect.

The largely positive responses to the Likert questions are contradicted by the student responses to open ended questions classified in Table 2, which revealed two broad categories of student problems, technical and personal. At present, the institution is addressing the problems of a technical nature while the personal problems raised by students have implications for the development of future ALNbased modules which are discussed below.

These negative comments are reinforced by the fact that $76 \%$ of students preferred the more familiar lecture-based environment for subject delivery though when prompted for suggested improvements to the module only $23.5 \%$ requested a return to traditional learning paradigms incorporating more paperbased handouts. Of the cohort of students used in this study only $24 \%$ expressed a preference for ALN-supported learning over a traditional paradigm. These observations are consistent with those of others [14] who claim that a lack of learner computer literacy as well as a reluctance to embrace the technology are significant barriers to deriving optimal benefit from ALNs. The apparent discrepancy between student responses to Likert-type questions and open-ended questions suggests that effective evaluation of future ALN-based modules must incorporate both types of statements.

Based on the results shown in Table 1, the cohort of students used in this study appeared to have a neutral attitude toward the introduction of ALN-supported learning (mean scores ranging from 2.024 4.095). This is disappointing since the innovations in delivery format should have benefited the type 
of student predominant in this cohort. However, the sample did acknowledge that there were significant problems gaining access to the online material, the most significant being described in Table 2.

However, a cautionary note emerges from these observations since it is apparent that there is an inverse correlation between IT Appreciation score and problems with infrastructure in students who pass the module. That is, those students who appreciate ALN-supported learning (low IT Appreciation score) were frustrated with the problems associated with accessing the online material. Based on the observations presented in this study staff in higher education considering a ALN-based approach to curriculum delivery must first ensure appropriate numbers of quality computers are in place and that the systems employed are reliable. These observations are consistent with those of other authors [15] who also suggests that "slow unreliable systems quickly lose the support of the user." Students who failed the module expressed a significantly greater preference for this type of ALN-supported learning than those who passed. However, it is not possible to attribute much weight to this observation since only 6 students who failed the module completed the IT Appreciation questionnaire. Not surprisingly, students who passed the module expressed a significantly greater preference for maintaining the current assessment regime than those students who failed the module. The alternative to the current assessment model was that newsgroup contribution also be assessed.

\section{B. The Use of the Asynchronous Communication Newsgroups}

Peer interaction has long been acknowledged to play a key role in the learning process [10]. However, based on the results of this study, only a small proportion of this interaction took place in the asynchronous newsgroup forum. When prompted to explain this non-contribution, students made a variety of comments, which have been divided into two general categories, technical and personal (shown in Table 4). Examples of personal statements made by students include:

"Computers make me nervous and depressed!"

"To be honest I am a computer unfriendly person and I find it such a mission to get into any sort of programme on ANY (student's emphasis) computer."

The rationale for introducing the asynchronous communication newsgroups was to facilitate the exchange of ideas and to allow students, who may not feel able to contribute to traditional classroom discussion to air their views after careful consideration in their own time. This medium was only partially successful despite staff adhering to recognised good practice for online discussion such as appropriate integration of the technology, engaging in rapid constructive feedback and prompting students with discussion points. It is possible that the students' perceptions of the "added value" to be gained from newsgroup contribution was insufficient to outweigh the learning curve and access issues. Only a small proportion of students contributed to the asynchronous newsgroup despite continual urging and encouragement from staff. Those students who did not contribute attributed their non-contribution to technical problems (Table 4) rather than a perceived absence of benefit. Foley and Schuck [16] have also described difficulties associated with system downtime and access resulting in learner resentment, while others [14] refer to a deficient technical infrastructure acting as a barrier to the benefits of technology. These problems ultimately lead to frustration with the technology despite a generally positive outlook on web-based tuition as in this study. Such dialogues, as took place within the newsgroup, tended to be limited to 1 or 2 exchanges as previously noted [17]. Perhaps the number of students contributing to the newsgroup could be increased by incorporating closer integration of online and off-line material or some assessed material in this medium (possibly group work), as suggested by others [11]. It is however, possible to tentatively suggest that newsgroup contribution may serve as a useful indicator of module performance. It would be interesting to compare the contribution of students in the ALN paradigm with that in the traditional classroom. In addition student age also contributes to module performance with the more mature students performing significantly better than younger students. In addition, mature students who contributed to the newsgroup performed best of all (Table 5) though no interaction effect was observed between age and contributory status. It is interesting to speculate on the existence of gender differences in newsgroup 
contributions since work in this field is inconclusive. Some workers [18] report gender differences in the use of asynchronous communication media in education students and others [19] demonstrate considerable gender similarity in attitude and use of asynchronous learning networks.

\section{Suggested Improvements}

Based on the observations presented in this report it appears that students do acknowledge the benefits of utilizing ALNs and participation in asynchronous discussion may assist the learning process. However, when students experience problems of either a technical or personal nature acceptance of the new technology is inhibited.

While problems of a technical nature can only be overcome with appropriate institutional support it is possible to utilise the personal problems highlighted in this study to inform the development of future ALN-based modules in this area.

With this in mind future modules designed using this paradigm should incorporate the following improvements:

Technical Issues

1) Ensure that a sound infrastructure incorporating sufficient numbers of computers of adequate specification with high speed internet access is in place prior to module delivery.

2) Provide adequate technical support.

3) Incorporate an external password system to enable "any time, any where" access to the online material.

4) Provide adequate training and practice time.

Personal Issues

1) Evaluate initial student familiarity with C\&IT to identify those in need of additional support / encouragement.

2) Incorporate a greater degree of guidance with the use of technology.

3) Introduce students to computer-mediated communication gradually in several modules.

4) Motivate students to utilise the technology possibly by incorporating online assessment or making compulsory the downloading of lecture synopses in advance of face to face class.

\section{CONCLUSIONS}

In conclusion the observations presented in this study indicate that though students of Human Nutrition and Human Nutrition \& Dietetics appreciate the advantages of ALNs, problems of a personal or technical nature may detract from this experience. These problems can be overcome by ensuring that an adequate institutional infrastructure is in place and by providing suitable guidance and motivation. It is important that these recommendations are met if the considerable time and effort invested by staff in the move to an ALN-based delivery paradigm is not to be wasted. Contribution to the asynchronous newsgroup plays a key role in the learning process since students who contribute on line perform best in the end of module examination. Mature students who contribute to the newsgroup perform best of all.

Student responses to Likert-type and open-ended questions on the IT Appreciation questionnaire generated contradictory answers. Thus evaluation of future modules in this area must incorporate both types of questions.

\section{ACKNOWLEDGEMENTS}

We would like to thank the LaTID staff at The University of North London for their inspiration and encouragement. Jan McEneany, Paul Walk, Nigel Marlow and Nick Silvester for their technological advice, and Drs. Martin Oliver and Julia Phelps for proof reading the manuscript and assisting with the categorisation of the response data. 


\section{REFERENCES}

1. Davies, M.L., and Crowther, D.E.A., The Benefits of Using Multimedia in Higher Education: Myths and Realities, Active Learning, Vol. 3, 1995. http://www.cti.ac.uk/publ/actlea/issue3/crowther/index.html

2. Sosabowski, M.H., Herson, K., and Lloyd, A.W., Enhancing Learning and Teaching Quality: Integration of Networked Learning Technologies into Undergraduate Modules. Active Learning, Vol. 8, 1998. http://www.cti.ac.uk/publ/actlea/al8pdf/sosabowski.pdf

3. Wright, N., and Cordeaux, C., Rethinking Video-conferencing: Lessons Learned From Initial Teacher Education, Innovations in Education and Training International, Vol. 33, No. 4, pp. 194-202, 1996.

4. Spennemann, D.R., Gender Imbalances in Computer Access Among Environmental Science Students, Journal of Instructional Science and Technology, Vol. 1, No. 2, 1996. http://www.usq.edu.au/electpub/ejist/spenne.htm

5. Schutte, J., Virtual Teaching in Higher Education: The New Intellectual Superhighway or Just Another Traffic Jam? 1996. http://www.csun.edu/sociology/virexp.htm

6. Teh, G.P.L., and Fraser, B.J., An Evaluation of Computer-assisted Learning in Geography in Singapore, Australian Journal of Educational Technology, Vol. 10, No. 1, pp. 55-68, 1994.

7. Phipps, R., and Merisotis. J., What's the Difference? A Review of Contemporary Research on the Effectiveness of Distance Learning in Higher Education. A report by The Institute for Higher Education Policy, Washington, DC, 1999.

8. Dearing, R., Higher Education in the Learning Society: Report of the National Committee of Inquiry into Higher Education, London, HMSO and NCIHE Publications, 1997.

9. Brown, A., Designing for Learning: What Are the Essential Features of an Effective Online Course, Australian Journal of Educational Technology, Vol. 13, No. 2, pp. 115-126, 1997.

10. Harasim, L., Online Education, Perspectives on a New Environment, Praeger, New York, 1990.

11. Hiltz, S.R. Impacts of College-level Courses Via Asynchronous Learning Networks: Some Preliminary Results, Journal of Asynchronous Learning, Vol. 1, No. 2, 1997. http://www.aln.org/alnweb/journal/jaln_Vollissue2.htm - Hiltz

12. Conole, G and Oliver, M., A Pedagogical Framework for Embedding C\&IT Into the Curriculum, Association for Learning Technology Journal, Vol. 6, No. 2, pp. 4-16, 1998.

13. Likert, R.A., A Technique for the Measurement of Attitudes, Archives of Psychology, Vol. 140, 1932.

14. Robinson, H., Smith, M., Galpin, F., Birchall, D., and Turner, I., As Good As IT Gets: Have We Reached the Limits of What Technology Can Do For Us? Active Learning, Vol. 9, pp. 50-53, 1998.

15. Pham, B., Quality Evaluation of Educational Multimedia Systems, Australian Journal of Educational Technology, Vol. 14, No. 2, pp. 107-121, 1998.

16. Foley, G., and Schuck, S., Web-based Conferencing: Pedagogical Asset or Constraint? Australian Journal of Educational Technology. Vol. 14, No. 2, pp 122-140, 1998.

17. Farquhar, J., McGinty, B., and Kotcho, C., The Internet As a Tool for Social Construction of Knowledge, Indianapolis, In: Association for Educational Communications and Technology, ERIC Document Reproduction Service No. ED 397 793, 1996.

18. Blum, K.D., Gender Differences in Asynchronous Learning in Higher Education: Learning Styles, Participation Barriers, and Communication Patterns, Journal of Asynchronous Learning Networks, Vol. 3, No. 1, 1999. http://www.aln.org/alnweb/journal/Vol3 issue1/blum.htm

19. Ory, J.C., Gender Similarities in the Use of and Attitudes About ALN in a University Setting, Journal of Asynchronous Learning Networks, Vol. 1, No. 1, 1997. http://www.aln.org/alnweb/journal/issue1/ory.htm

\section{ABOUT THE AUTHORS}

Graham Shaw received his Ph.D. from Aston University in 1983. He spent 10 years as a senior lecturer in the school of Health and Sports Science at the University of North London before moving to The Californian College of Podiatric Medicine in 1999. He is an active member of The Society of General Microbiology and The British Society of Gastroenterology. His research interests centre on the role of Helicobacter pylori in peptic ulcer disease and the impact of C\&IT in higher education.

Willy Pieter received his Ph.D. in physical education from the University of Oregon. He is currently involved in leading international research programs in health-related fitness of university students as well as the profiling of competitive athletes in the Philippines. He has recently developed an interest in computer applications in teaching. Dr. Pieter has previously published in sports science journals. 